Patient journey mapping: Integrating digital technologies into the journey

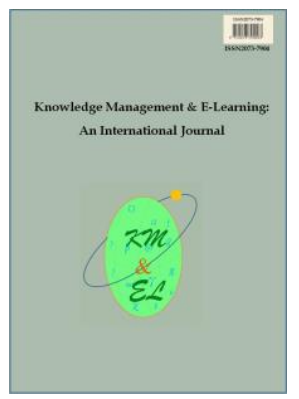

Elizabeth M. Borycki

Andre W. Kushniruk

Evangeline Wagner

Ryan Kletke

University of Victoria, Victoria, BC, Canada

Knowledge Management \& E-Learning: An International Journal (KM\&EL) ISSN 2073-7904

Recommended citation:

Borycki, E. M., Kushniruk, A. W., Wagner, E., \& Kletke, R. (2020).

Patient journey mapping: Integrating digital technologies into the journey.

Knowledge Management \& E-Learning, 12(4), 521-535.

https://doi.org/10.34105/j.kmel.2020.12.029 


\title{
Patient journey mapping: Integrating digital technologies into the journey
}

\section{Elizabeth M. Borycki*}

School of Health Information Science

University of Victoria, Victoria, BC, Canada

E-mail: emb@uvic.ca

\author{
Andre W. Kushniruk \\ School of Health Information Science \\ University of Victoria, Victoria, BC, Canada \\ E-mail: andrek@uvic.ca
}

\section{Evangeline Wagner}

School of Health Information Science University of Victoria, Victoria, BC, Canada

E-mail: evangelinemwagner@uvic.ca

\section{Ryan Kletke}

School of Health Information Science University of Victoria, Victoria, BC, Canada

E-mail: rkletke1@uvic.ca

*Corresponding author

\begin{abstract}
Patient journey mapping represents a new way of reasoning about continuity of care, reducing wait times and improving patient safety. Patient journey mapping allows users such as health professionals, patients and policy makers to identify technologies that can be used to support patient care. Patient journey maps allow one to visualize a patient's journey and at the same time understand, where gaps in patient care exist. In this paper we discuss a novel approach to patient journey mapping for supporting reasoning and decision making about how technological tools could be integrated into a patient's health journey. The approach allows for reasoning surrounding technologies in the patent's digital ecosystem.
\end{abstract}

Keywords: Patient journey mapping; User journey mapping; Patient safety; Ambient assistive living; Remote monitoring; Digital health; Cancer informatics

Biographical notes: Dr. Elizabeth Borycki is a Professor in the School of Health Information Science at the University of Victoria, Canada. She is the Director of the Global Laboratory for Digital Health Innovation at the University of Victoria, Canada. Elizabeth conducts research at the intersection of safety science, human factors and technology in the field of health 
informatics. She is also a Clinician Scientist with the Michael Smith Foundation for Health Research, Vancouver, Canada. Elizabeth's other research interests include safe health technology design, software engineering and implementation science involving health technology. Elizabeth is internationally recognized for her research in health informatics.

Dr. Andre Kushniruk is Professor and Director of the School of Health Information Science at the University of Victoria, Canada. He has published widely in the area of health informatics and is known for his work in the usability of healthcare information systems. Dr. Kushniruk conducts research in a number of areas and he focuses on developing new methods for the evaluation of information technology in healthcare. Dr. Kushniruk has been a key researcher on a number of national and international collaborative projects. His work includes evaluation of systems for use by healthcare providers, patients and citizens.

Evangeline Wagner is a student at the University of Victoria studying Health Information Science. She is a Research Analyst for the Global Laboratory of Digital Health Innovation. Her interests include technologically assisted living, patient safety, public health and the use of robotics in healthcare.

Ryan Kletke is a student in the University of Victoria Masters program in the School of Health Information Science. He is a Research Analyst for the Digital Empathy Project. His research interests include Data Science and the development of Decision Support Tools for the Elderly.

\section{Introduction}

Patient journey maps represent a practical and visual method that can be used for supporting reasoning about continuity of care, reducing wait times and improving patient safety. Furthermore, these maps could be extended to identify opportunities to add technological components that may be used to support patients throughout their treatment journey (e.g., for cancer care). They offer an opportunity for health technology professionals to identify technologies that address specific types of problems encountered and documented by patients. In this way, patient journey maps could be used to visualize how technology can be integrated into what is typically a linear and longitudinal process. In addition, such maps could enhance digital health strategy planning at a policy level while at the same time allowing for a way to enhance the patients' own ability to use technologies in their own homes to care for themselves. In this paper we describe a novel approach to using patient journey mapping to identify areas where technology could be applied to optimize the patient's experience and health outcomes.

Understanding a patients' healthcare journey is one of the most important activities that the health informatics and technology community can engage in prior to designing, developing, procuring and/or implementing a new technology in a patient's digital ecosystem. Such engagement is essential to ensuring the continuity of patient care, timely interventions and patient safety (Ash et al., 2007; Borycki, 2019; Househ et al., 2014). Patients and their caregivers are well-informed consumers of digital health technologies (Reid \& Borycki, 2011). Today's patient uses technology to communicate with health professionals and caregivers (e.g., family) as well as self-manage their health over the course of an acute or chronic illness (Catley et al., 2008). In a digitally mature world, and in other cases, a crowded healthcare technology ecosystem, patients are 
experiencing difficulty in navigating healthcare and determining how health technologies fit into their lives. Furthermore, over the past 20 years there have been significant changes in our healthcare system, leading to more complex treatments (Plsek \& Greenhalgh, 2001) and the introduction of opportunities for patients to "fall through the cracks" from an organizational, health professional and technology perspective (Santibáñez et al., 2009). This is especially the case during transitions in care when differing organizations, technologies and health professionals provide healthcare at a system level.

Today, patients receive care from a number of health professionals, located in differing organizations. Patients also use a number of technologies over the course of a lifetime (Househ et al., 2014). Patient and caregiver system navigation has become more complex over time. The introduction of new health system level technologies that are used by patients, caregivers, and health professionals have made the healthcare system complex (Cresswell \& Sheikh, 2013). Therefore, it is often unclear to patients or their families how these health system technologies integrate into a patients' digital ecosystem and ultimately into their personal health journeys.

Patient journey maps could allow for testing of new technologies and tools that may be used to tailor self-management and rehabilitative interventions for patients and may change over the course of a patient's healthcare journey (i.e., in response to changes in the patients' condition such as improvements or deterioration). For example, alerts and reminders could be tailored to the patient and their informal caregiver to encourage better self-awareness of physiologic processes and when to seek care, and this could be highlighted in patient journey maps. In other cases, alerts and reminders could be triggered at appropriate times during the patient journey so that health professionals can intervene when wait times or fragmentation in care may lead to delays in diagnostic testing, and treatment. Patient journey maps could be focused on transitions in care that are time oriented and impact patient survival or may increase costs associated with treatment of disease if not immediately addressed. These technologies may include wearable sensors or medical devices that measure physiologic status, measure symptoms such as pain and/or symptom management tools that could be accessed via a patient portal and devices owned by a patient and/or their family member (e.g., mobile phone or smart watch). In addition to this, rehabilitative devices could be added to the patient journey. Patient journey mapping could therefore be used as a vehicle for reasoning and discussing where along the patient's journey such technologies could best be integrated.

Along these lines, policy makers have been flooded with a plethora of technologies from vendor organizations. Policy makers find it difficult to develop healthcare system wide digital strategies that leverage currently implemented technologies while at the same time identifying technologies that may be able to address health system gaps, safety issues and fragmentation of care. New modelling tools are needed to support healthcare policy makers reasoning, decision making, and technology strategy policy making. Created tools need to support continuity of care, reduction in wait times, patient safety and patient health journeys. Patients' and their family members need technology tools that can integrate into their own digital ecosystem and support their participation in their own healthcare. Such research into modelling and developing digital tools is critical to ensuring health information is not lost, reducing fragmentation of services, shortening wait times and improving patient safety.

In this paper, we describe a novel approach to the use of patient journey mapping as a healthcare systems and technology system-modelling tool to identify and expose wait times, fragmentation and safety issues. The approach may be used to guide digital 
strategy for policy makers and support patients throughout their healthcare journey. This novel tool can help to design digital strategy, identify existing and develop new technologies that can be used in a patient's technology digital ecosystem. The approach describes the patient's journey and can be used to illuminate the patient's existing technology resources, thereby allowing for the creation of a tailored, patient specific ecosystem. We know that when technology is poorly tailored to each patient's needs or it is not integrated, the system of care may become fragmented and discontinuous. The approach also describes the application and use of a patient journey mapping tool to identify healthcare gaps and evidence-based technologies that could be used to overcome fragmented healthcare systems. To date, there has been limited research that has been published using patient journey mapping as a tool to enhance digital health strategy while at the same time reducing fragmentation of care (with a focus on technology's role in promoting continuity of care, reducing wait times and improving patient safety). We use a published case report to illustrate the use of the approach (BCPSQC, 2019). Before we begin, let us review the published literature in the area and its relationship to technological complexity in healthcare and consumer digital ecosystems.

\section{Background}

In this section of the paper, we describe literature we have reviewed that is relevant to the integration of health technology into patient journey mapping. We begin with a discussion of technological complexity in healthcare and the need for consideration of the digital ecosystem of patients. This will be followed by a discussion of the current literature describing how patient journey mapping can be integrated into healthcare.

\subsection{Technological complexity in healthcare}

There has been substantial growth in the number of health technologies implemented in healthcare systems around the world; for example, electronic medical records (EMRs) are common in physician offices and primary care clinic settings (Guerrazzi, 2020; OECD, 2018). Almost $100 \%$ of physicians (and nurse practitioners) have adopted EMRs for use in their clinics and offices among the OCED countries (OECD, 2018). Electronic health records (EHR) are also being used in hospitals around the world, and their implementation is moving towards $100 \%$ adoption in many healthcare organizations (Kharrazi et al., 2018). Health professionals expect to know how to use these technologies. EHR's have become a standard part of health professional educational programs (Gagliardi \& Turner, 2016). Robots are being used to support some surgeries, medication dispensing, and personal care activities. The use of these technologies by health professionals is growing, extending traditional intervention and patient treatment modalities and changing the patient journey with their introduction (Khan \& Anwar, 2020; OECD, 2018).

\subsection{Consumer development of digital ecosystems}

Consumers are buying wellness, illness and chronic disease management technologies to support their health and independent living. Consumer use of mobile health apps and sensors is growing exponentially. Consumers are buying technologies that support their wellness and ability to live independently in their homes (Eysenbach, 2000). Homes are becoming "smart" or "intelligent" with the introduction of technologies tailored to individual needs and are being modified over a lifetime to support changes in health 
status. Voice activated consumer technologies that interface with appliances such as fridges, stoves, lighting, cleaning tools such as robotic mops and vacuum cleaners as well as smart televisions and laptop computers are being used by consumers to support health. The technologies are everywhere, yet there are a lack of healthcare technologies that can integrate into a consumers digital ecosystems so that care is more tailored, continuous, faster and safer.

\subsection{Healthcare organizations, healthcare systems and digital health strategy}

Along these lines, healthcare organizations are struggling to achieve improved patient outcomes and efficiencies in an increasingly digitally connected world. Digital health initiatives are underfunded and often fail to be implemented or used to their fullest functionality (i.e., limiting their use) (Gill \& Borycki, 2017). Consumers are asking: "Why don't health technologies integrate with my digital ecosystem?" "Why do I have access to technologies that support my healthcare, but my healthcare organization is using outdated technologies? Why can't I continue to use technologies that currently support me in my home and that I have implemented? There has emerged an important need to develop and extend modelling approaches to understand health systems and health technologies, including how they may be integrated with consumer technologies in a way that is specific to the patients' illness(es) and their physical and cognitive limitations. Such work is critical to informing technology design, development, procurement and implementation (Waldemarin \& de Farias, 2018). In addition to this, policy makers are forming digital strategy in a health technology context that is flooded with options and it has become difficult to identify digital strategies that leverage existing technologies and have a strong evidence-base for their use. Patient journey mapping has emerged as a potential solution or tool for supporting policy maker decision making and patient needs for technologies tailored to their existing digital ecosystems going forward.

\subsection{Patient journey mapping defined}

Many health technologies have been studied for their effectiveness in improving patient outcomes. Many of these studies have focused on how a technology improves the safety, efficiency and effectiveness of patient care (Chaudhry et al., 2006). To date, only a limited number of researchers have explored the use of patient journey mapping in a healthcare context, and only a small number of researchers have begun to explore patient journey mapping with attention to the technologies that might better integrate patient care, reduce wait times and improve patient safety. Patient journey mapping is one potential solution. The patient journey map has its origins in the software literature in the area of user mapping. The patient journey map is an extension of user maps (Kalbach, 2016) and focuses on patients. The tool itself is useful in discovering and collecting information about healthcare processes and user experiences (e.g., for patients, caregivers and health professionals). To date, only a limited number of articles have been indexed in Pubmed, IEEEXplore and Web of Science combined, describing the application and use of patient journey maps in healthcare to improve processes. In addition, the integration of health technologies into patient journey mapping has remained to be explored. This area of research represents a novel path forward for modelling and addressing some of the issues encountered in healthcare outlined above. 


\subsection{Patient journey mapping research in healthcare}

Patient journey mapping as a research area is in its infancy with many early works exploring the potential application and use of the tool (Martin et al., 2011; Parush, 2019). Parush and colleagues first introduced patient journey mapping to healthcare in 2014. The researchers described how patients, health providers and EMRs intersect during a patient visit to a hospital clinic. The map illustrated how patients, health professionals and technologies can be interleaved to support hospital clinic activities, and how if a clinic is not adequately instrumented with computers, scanners and printers as well as the privacy and confidentiality of patients may be compromised. The research also illustrated how additional workstations could improve the efficiency and effectiveness of the clinic by providing health professionals with increased access to EMRs using technology (Parush et al., 2014). In a subsequent study, Percival and McGregor (2016) used a case study approach to examine the understandability and usefulness of patient journey maps. Their research took place in a forensics and an adult rehabilitation ward. Findings from the study revealed health professionals had a better understanding of their roles, activities and processes following their participation in a patient journey mapping exercise. The authors identified that communication could be improved between health professionals by using the approach. McCarthy et al. (2020) developed an Integrated Patient Journey Mapping Tool (IPJM). The aim of this work was to develop a tool that "simultaneously considered the factors of performance improvement, regulatory constraints, and patient experience".

More recently, Meyer (2019) created a patient journey map from a case report describing a patient's journey. In this research, the investigators made four important observations: (1) the patient's health goal must be visible, (2) there is a need for transparency between patients and health professionals, (3) there is a need for shared decision making and (4) there is a need for closed loop communication. In a related study, researchers from Australia mapped a patients' journey through a regional Australian emergency department. The researchers used UML modelling approaches to highlight emergency room bottle-necks (leading to increased wait times for care) in an attempt to decrease overcrowding. Through their work, the researchers discovered the physical layout of the emergency room, triage processes and hospital bed status affected emergency room wait times (Meyer, 2019).

To date, most of these studies have focused on improving healthcare processes within confined organizational structures such as clinics, emergency departments and nursing units within a healthcare organization. None of these studies have used the patient journey map at a healthcare systems level - as tool that can be used to plan digital strategy aimed at eliminating gaps in care across organizations. In summary patient journey mapping has been used to identify process, technology resourcing, privacy and wait time issues while at the same time capturing information about patient behaviour, feelings, motivations and the attitudes of health professionals across patient episodes of care. Such research is important as it can be used to improve healthcare. There is a need to address healthcare system issues and patient journey mapping may prove to be an essential tool for decreasing fragmented care for patients and across healthcare systems.

\section{Methods}

A case report can be used to develop a patient journey map to enhance digital health planning and to improve continuity of care and safety at the patient level. Prior patient journey mapping research suggests case reports can be used to effectively generate, 
informative and useful patient journey maps (Meyer, 2019). Using Meyer's approach, we created a novel patient journey map focused on improving continuity of care and safety at a health systems level.

\subsection{Selection of a relevant case report}

We first identified a case report that could be used to inform healthcare systems' improvements and digital health strategy. We chose a case report that described a cancer pathway for patients in one jurisdiction in Canada. The original aim of the case report was to "explore and capture the emotional, mental and social experiences of individuals and groups interacting with a complex [health] system" (BCPSQC, 2019). The document provides a fulsome description of a patient journey, but does not use patient journey mapping software modelling tool. The report was robust and provided in-depth descriptions. The report also drew on the experiences of patients who had received treatment for cancer. The document does not examine what technologies could be used to improve continuity of care (i.e., between healthcare organizations), reduce wait times or improve safety. This case report describes the experiences of 10 cancer patients and their informal (i.e., family) caregivers in one Canadian province. The report details the mental, emotional and social issues of patients receiving cancer treatment (BCPSQC, 2019).

\subsection{Context}

The patient journey mapping exercise took place in the context of Canada's healthcare system. Healthcare in Canada is publicly funded (i.e., citizens are taxed and monies from taxes are used to pay for healthcare services). Taxes are collected by the federal government and these monies are transferred to the provinces. Most of Canada's healthcare delivery is done through a decentralized network of health insurance plans. Canada's territorial and provincial governments coordinate healthcare service administration and delivery. According to Martin et al. (2018), Canada's healthcare system has long waits for elective care and is characterized as having systemic, pervasive health inequities in the way that healthcare is delivered. These health inequities are particularly prevalent among Indigenous, minority and vulnerable Canadian populations (Martin et al., 2018).

The case report outlined the experiences of patients and their families. Cancer care is provided by three types of organizations in the province:

- Physician offices and clinics, where primary care physicians (and nurse practitioners) provide care, initiate tests and procedures that identify a cancer,

- Physician surgical care providers, who have their own offices and clinics and provide surgical care within a regional health authority (usually located in the region where the patient resides)

- A province wide cancer agency that provides services via a network of clinics, regional cancer centers and other facilities throughout the province.

Primary care physicians often initiate the patient's cancer care journey. Treatment usually begins with a primary care physician initiating diagnostic testing for a possible cancer. This work is then followed by referrals to specialists such as surgeons (who perform surgeries in regional health authorities to remove cancers) and the provincial cancer agency (where oncology services such as radiation therapy, chemotherapy and 
immunotherapy are provided). The cancer agency also provides follow-up services after treatment for remission and recurrence of cancer (Greenwald, 2017; Health, 2020).

\subsection{Mapping procedure}

The authors used a patient journey mapping tool to diagram the typical cancer patient journey as outlined in the case report. The authors extended the original description to include ways in which technology could be used to support the patient throughout his or her treatment and care process. Our extensions include identifying potential ways to reduce fragmentation of care across organizational settings, wait time reduction and improvements to patient safety using healthcare and patient facing technologies.

We used the UXpressa ${ }^{\circledR}$ patient journey mapping tool as a base and then extended/modified it to illuminate these gaps and periods of fragmentation in care as described in the case report. Initially, we extracted data about the typical care process from the case report and populated a standard patient journey map (see BCPSQC, 2019). The initial template needed to be extended to fully diagram the patient's journey as described in the case report and to include the role of technologies. This resulted in our adding a row at the top of the patient journey map to include the key phases of the cancer treatment process. The cancer pathway includes several key phases (i.e., pre-diagnosis, primary care doctor visits, diagnostic testing, the diagnosis, choosing a treatment, treatment and remission). This information was used to provide an overall framework for describing the patient's journey using the UXpressa ${ }^{\circledR}$ tool. Following this, we extracted the patient goals and actions for each phase in the pathway and storyboarded the map (see Fig. 1: Patient Journey Map).

After this work was completed, a group of researchers worked together and brainstormed the technologies (patient, caregiver and healthcare organization owned) that would provide a seamless integration into each phase of the cancer pathway. The approach focused on decreasing fragmentation in care while at the same time improving communication between the patient, caregivers and healthcare providers throughout the cancer testing and treatment process as described in the case report. The brain storming process involved leveraging technologies typically owned by most patients in their own digital ecosystem (including platforms and devices) and those typically used by healthcare organizations. The ideas emerged from the published evidence-based health informatics literature. The approach builds on initial work done by Parush et al. (2014) that documents how clinic processes are interleaved with technology. Our work adds a novel extension to the research of Parush et al. (2014) by extending the patient journey mapping process from a single patient visit to a clinic to the full care process across healthcare practitioners and organizations in a healthcare system. The process allowed for identification and application of technologies to occurrences, where patients' and families experienced fragmentation of care. In addition to this, we added technologies typically used by consumers in their homes to the map to observe how the consumer would access information and manage their treatment using consumer-oriented, evidence-based technologies.

This patient journey mapping process began with adding a row to the top of the map that describes the stages of the healthcare process from a diagnostic imaging perspective, beginning with identifying a cancer through to its treatment and remission (see Fig. 1). Underneath this row, we added storyboard images and depictions reflective of the process to draw our attention to the key aspects of the healthcare that could be enhanced using technologies. This row provides an overview of the key aspects of the healthcare process and serves to stimulate discussion about evidence-based technologies 
and digital strategy. We then added rows for patient goals and actions in the care process. Lastly, a row was added for "Technological Opportunities" that could enhance the care process (see Fig. 1). The approach allows for technology to be integrated into the patient journey to be considered along the stages of the patient journey (indicated along the top of the figure, going from "Pre-Diagnosis" through to "Continued Recovery").

\begin{tabular}{|c|c|c|c|c|c|c|c|c|}
\hline & PRE-DIAGNOSIS & PRIMARY DOCTOR'S VISIT & DIAGNOSTIC TESTING & DIAGNOSIS & CHOOSING ATREATMENT & TREATMENT & REMISSION & CONINUED RECONERY \\
\hline & Noticing something is wrong & Intitally assessing the patient & Gathering info & Scheduling an appointment & Decision Making & Decision Making & Recovery & Follow up \\
\hline Storyboard & Pholot by Gan Khoon Lay & Photo by: Sahua D. & Photo by. Astatine Lab & Photo by: Aratat Uddin & Photo by:Adrien Coquet & 쉬랑 & Photo by. Adrien Coquet & Photo by: Gregor Cresnar \\
\hline Patient's goals & $\begin{array}{l}\text { - Make an appointment } \\
\text { with their doctor. }\end{array}$ & $\begin{array}{l}\text { - Arrive at the office on } \\
\text { time. } \\
\text { - Tell the doctor all of their } \\
\text { symptoms. }\end{array}$ & $\begin{array}{l}\text { - Schedule and attend all } \\
\text { appointments. } \\
\text { - Contact the primary } \\
\text { care doctor if symptoms } \\
\text { become worse. } \\
\text { - Follow up after the tests } \\
\text { are complete. }\end{array}$ & $\begin{array}{l}\text { - Understand the diagnosis, } \\
\text { create a support system, and } \\
\text { work with the primary care } \\
\text { doctor. }\end{array}$ & $\begin{array}{l}\text { - Meet with the oncologist. } \\
\text { - Consider all of the treatment } \\
\text { options. } \\
\text { - Try to address the financial } \\
\text { costs of the illness. }\end{array}$ & $\begin{array}{l}\text { - Communicate with the health } \\
\text { professional team about wants } \\
\text { and needs. } \\
\text { - Consider all the options. } \\
\text { - Follow treatment directions } \\
\text { communicated by the health } \\
\text { care team. }\end{array}$ & $\begin{array}{l}\text { - Understands what is } \\
\text { required to manage ones } \\
\text { care. } \\
\text { - Seek care for remission } \\
\text { including counselling and } \\
\text { help with a normal life. } \\
\text { - Follow the plan designed } \\
\text { with the health } \\
\text { professionals. }\end{array}$ & $\begin{array}{l}\text { - Communicate with the } \\
\text { health provider about } \\
\text { their progress, absence } \\
\text { of symptoms and } \\
\text { medications } \\
\text { - Follow and adjust ones } \\
\text { health plan with the } \\
\text { physician. }\end{array}$ \\
\hline Patient's actions & $\begin{array}{l}\text { - The patient notices that } \\
\text { something is wrong and } \\
\text { makes an appointment } \\
\text { to see their physician. }\end{array}$ & $\begin{array}{l}\text { - The patient explains their } \\
\text { symptoms. } \\
\text { - The doctor conducts a } \\
\text { physical exam. } \\
\text { - Additional testing is } \\
\text { ordered by the doctor. }\end{array}$ & $\begin{array}{l}\text { - The patient undergoes } \\
\text { testing (as orderd by the } \\
\text { doctor). }\end{array}$ & $\begin{array}{l}\text { - The patient is diagnosed with } \\
\text { cancer. } \\
\text { - The primary care physician } \\
\text { explains the diagnosis, what it } \\
\text { may mean for the patient, and } \\
\text { encourages the patient to ask } \\
\text { questions. }\end{array}$ & $\begin{array}{l}\text { - The patient is referred to a } \\
\text { specialist that is familiar with } \\
\text { the patient's specific type of } \\
\text { cancer. } \\
\text { - A care plan is produced in } \\
\text { collaboration with different } \\
\text { specialists treating the patient. } \\
\text { - The patient considers options } \\
\text { and understands the risks } \\
\text { associated with the options. }\end{array}$ & $\begin{array}{l}\text { - The patient decides on a } \\
\text { treatment plan with the support } \\
\text { of their care team. } \\
\text { - The patient is referred to } \\
\text { another specialist to perform } \\
\text { the treatment if necessary (e.g. } \\
\text { surgeon) }\end{array}$ & $\begin{array}{l}\text { - The treatment was } \\
\text { successiul (i.e. there is no } \\
\text { active cancer). } \\
\text { - The patient goes to fewer } \\
\text { doctor appointments, and } \\
\text { begins to return to a more } \\
\text { normal life. } \\
\text { - The patient realizes that } \\
\text { remission isn't a cure. } \\
\text { - The patient continues with } \\
\text { health visits, diagnostic } \\
\text { scans and follow-up. } \\
\text { - A plan is developed to } \\
\text { manage health long term. }\end{array}$ & $\begin{array}{l}\text { - The patient engages in } \\
\text { regular follow-up (e.g. } \\
\text { scans and vists to their } \\
\text { doctor). } \\
\text { - Care plans are created to } \\
\text { incorporate traumatic } \\
\text { stress therapy. } \\
\text { - Medications are re- } \\
\text { evaluated and changed } \\
\text { as needed. }\end{array}$ \\
\hline $\begin{array}{l}\text { Technological } \\
\text { Opportunities }\end{array}$ & $\begin{array}{l}\text { - Create a patient portal } \\
\text { that is online for } \\
\text { patients to access } \\
\text { - Receive information } \\
\text { about self-care and } \\
\text { alerts about their } \\
\text { healthcare. }\end{array}$ & $\begin{array}{l}\text { - Ensure the patient has } \\
\text { access to their test } \\
\text { schedules and results via } \\
\text { a patient portal. } \\
\text { - Ensure the patient } \\
\text { receives alerts and } \\
\text { reminders via the portal } \\
\text { and mobile phone about } \\
\text { appointments. }\end{array}$ & $\begin{array}{l}\text { - Ensure that the patient } \\
\text { has access to their test } \\
\text { schedules and results } \\
\text { via a patient portal } \\
\text { - Ensure the patient } \\
\text { receives alerts and } \\
\text { reminders via the portal } \\
\text { and mobile phone about } \\
\text { appointments and } \\
\text { follow-up. }\end{array}$ & $\begin{array}{l}\text { - Electronic Care Pathway for } \\
\text { guidance and support } \\
\text { throughout diagnosis } \\
\text { - Can include videos, written } \\
\text { information, questionnaires a } \\
\text { nd electronic tools for self } \\
\text { education about cancer and } \\
\text { monitoring of health } \\
\text { symptoms. } \\
\text { - Can also include alerts and } \\
\text { reminders to be sent to health } \\
\text { professionals if the patient } \\
\text { does not meet their goals. } \\
\text { - Includes } \\
\text { data visualisations of patient } \\
\text { progress. }\end{array}$ & $\begin{array}{l}\text { - Standardise communication } \\
\text { and referral system between } \\
\text { physicians so patient } \\
\text { information is clearly } \\
\text { transferred throughout the } \\
\text { journey. } \\
\text { - Can include videos, written } \\
\text { information, questionnaire } \\
\text { data and electronic tools for } \\
\text { self monitoring of heath. } \\
\text { - Can also include alerts and } \\
\text { reminders to be sent to } \\
\text { health professionals if the } \\
\text { patient does not meet their } \\
\text { goals or complete tasks. } \\
\text { - Can include visualisations of } \\
\text { patient progress. }\end{array}$ & $\begin{array}{l}\text { Standardise communication } \\
\text { between physicians to ensure that } \\
\text { patient information is clearly } \\
\text { transferred to different offices. } \\
\text { - Can include videos, witten } \\
\text { information, questionnaires and } \\
\text { electronic tools for self } \\
\text { monitoring of health symptoms. } \\
\text { - Can also include alerts and } \\
\text { reminders to be sent to health } \\
\text { professionals if the patient does } \\
\text { not meet their goals or } \\
\text { complete taskss } \\
\text { - Can include visualisations of } \\
\text { patient progress. }\end{array}$ & $\begin{array}{l}\text { - Create an online web } \\
\text { application avalable via } \\
\text { patient portal for cancer } \\
\text { remission support to help } \\
\text { patients re-integration into } \\
\text { society, including crisis } \\
\text { resources } \\
\text { - Can include videos, } \\
\text { witten information, } \\
\text { surveys and electronic } \\
\text { tools for self monitoring } \\
\text { of health symptoms. } \\
\text { - Can also include alerts } \\
\text { and reminders to be } \\
\text { sent to health } \\
\text { professionals if the } \\
\text { patient does not meet } \\
\text { their goals }\end{array}$ & $\begin{array}{l}\text { - Utilize an online portal for } \\
\text { patients and physicians } \\
\text { to track and monitor the } \\
\text { patient's testing and } \\
\text { recovery process } \\
\text { - Patients and providers } \\
\text { must be able to access } \\
\text { this portal to ensure that } \\
\text { all follow-up } \\
\text { appointments and scans } \\
\text { are completed } \\
\text { - Can include videos, } \\
\text { written information, } \\
\text { surveys and tools for } \\
\text { self monitoring of } \\
\text { health symptoms. } \\
\text { - Can also include alerts } \\
\text { and reminders }\end{array}$ \\
\hline
\end{tabular}

Fig. 1. Patient journey map 
Thus, we have made a novel extension to the patient journey map to include ways in which technologies could be used to support the patient throughout the treatment and care process at a systems level from hospital to outpatient treatment to home. Therefore, our focus in identifying evidence-based technologies is to address these gaps based on prior research (i.e., an evidence-base) and what could be applied at a healthcare systems level over time. This process of using the patient journey mapping tool to stimulate filling healthcare systems gaps using proven health technologies that could address gaps in care, proved to be a powerful approach for visualizing health technology systems that could be applied at a healthcare systems level using a focused strategic approach to guide policy making.

\section{Experiences to date}

Data were successfully extracted from the case report (described above) to create a unique patient journey map for cancer patients that integrates consideration of patient centred technology. To do this, the data were successfully inputted into the patient journey map software (in UXPressia ${ }^{\circledR}$ ). The initial patient journey map did not provide sufficient detail to map and apply a range of evidence-based technologies that could potentially improve continuity of care while at the same time improving patient safety both at a patient and healthcare systems level. The patient journey map was modified to support health technology professional reasoning and reflection on how this could be done. It was identified that health informatics/health technology professionals needed to populate the patient journey map with information about the current patient diagnostictreatment journey, followed by an examination about how technologies could be applied to improve continuity of care, support wait time management and improve communication between health professionals, patients and their families.

With a focus on identifying technologies that could be implemented to reduce fragmentation of patient care and improve wait time tracking for patients and caregivers (i.e., formal and informal caregivers) the researchers brainstormed technology solutions that could be implemented to:

- Improve continuity of care

- Decrease wait times

- Enhance patient safety

From the discussion among the researchers, the patient journey mapping exercise led to the identification of several technology solutions customized to support this process. Prominent among these technology solutions is the patient portal. A patient portal may support patient and informal caregivers throughout their cancer treatment (Han et al., 2019). The patient portal would allow for ubiquitous access to information about diagnostic test, health professional and treatment appointments throughout the healthcare process. Here, the patient would be able to view appointments (i.e., when they are booked and the length of time between appointments) (Han et al., 2019). A decision support tool could be integrated with the patient portal (Seljelid et al., 2020) to alert the primary care of practitioners, specialists physicians and patients if an appointment was booked that was outside the published norms for wait times for that condition. This could be done in several ways as part of an electronic record (for health professionals), a patient portal linked to a smart watch or mobile device (for patients and caregivers) (Han et al., 2019; Mamlin et al., 2016). This would allow the primary care practitioner to work with specialists to identify wait times outside of published norms. This could involve alerts 
presented to patients about wait times taken between key transitions in care such as receiving positive diagnostic test results and appointments to specialists to begin the initiation of treatment. As well, such alerts could be triggered for primary care and specialist physicians during transfer between treatment modalities and health settings such as surgery, radiation therapy, chemotherapy and immunotherapy are outside of published norms for the specific disease. Such alerts may enhance patient survival (i.e., some cancer outcomes are improved if the treatment is initiated within a set period of time) and may reduce costs, preventing progression of the disease and require more intensive or expensive interventions (Van den Bulck et al., 2018).

To address information needs about the disease and self-care approaches, a patient portal could be populated with electronic care pathways that outline activities patients and their informal caregivers need to undertake daily (as prescribed by members of the healthcare team). This information could include video (demonstrating activities), written information (to follow), videos (demonstrating activities covered in the healthcare setting, but requiring reinforcement) and tools that the patient could complete to monitor health symptoms throughout their healthcare experience. A patient and caregiver could complete an online questionnaire that allows them to catalogue their symptom experience. Following this, a health professional could be alerted to patient experiences of increased pain or other symptoms (Sulieman et al., 2020). Such alerts would trigger the health professional to respond to the patient. The patient could be alerted to their symptom experience (using wearable technologies) being outside the published norms and be given information that would lead to contacting health professionals and about methods for symptom management (Sulieman et al., 2020; Tierney et al., 2018). Such information could be presented to patients using visualizations that document past performance and the current state of their health. The visualizations could be used to support patient decision making to seek out care or support patient self-management of their symptoms (depending on the unique needs of the patient).

With the increase in the number of technologies that could be used to support patient management such as sensor devices and medical devices used to measure physiologic function (e.g., thermometers), a customized plan could be integrated with the patient portal technology to support physiologic and rehabilitative activities that may change from one stage in the treatment process to another. Here, alerts could be sent to health professionals, if the patient begins to experience physiologic changes noted by sensors. Such alerting may signal an acute care event or the need for more intensive or alternate intervention if the patient was no longer meeting rehabilitative targets (Tierney et al., 2018).

\section{Discussion}

New approaches and methods are needed to support reasoning and decision making about what technologies can be used to support patients during their health journeys. Nowhere is this more relevant than in the area of cancer care. In this paper we have described our approach to creating patient journey maps that integrate description of the stages patients go through with the potential use of health technologies to support them in their journey. This approach is innovative and allows for supporting of future discussion around how and when different technologies can best be brought to bear on improving the effectiveness, efficiency and safety of healthcare from a patient perspective. Thus, the approach can be used to both describe individual cases as well as at a broader, more generic policy level to help in reasoning about where and how technology can be best 
deployed from the patient and caregiver perspectives. A number of limitations and potential future extensions of this work can be identified, as described below.

The first consideration is that a case report was used to develop the patient journey map. Case reports are not representative of all patient journeys nor do they take into account the specific tests, treatments and rehabilitative approaches that are associated with specific cancers (or even the unique patient's needs). There would be a need to create a patient journey map with patients, their caregivers and then work with health informatics professionals to identify suitable tools and technologies to incorporate in the patient journey. Ideally, this would be an iterative process that includes patients, health professionals involved along the patient's journey and health technology professionals who have specific knowledge and expertise of the technologies that would be suitable to implement. A spiral model of user patient journey mapping and technology development would need to be used. Here, all parties would be involved in identifying gaps and issues as well as technological solutions at each stage in the healthcare process.

Furthermore, our current map assumes a linear process. Given that treatment of disease, for some patients, this may involve responding to recurrence of disease and in some cases re-application of specific treatment modalities as there is a need to develop maps that allow for repetition of specific parts of the healthcare process or new pathways to be engaged. There is a need to develop wait time based, symptom based and decision support tools for health professionals and patients that can be triggered during the patient journey so that the appropriate professional, patient, and caregiver alerts and reminders can act to prevent delays in care and additional costs associated with treating more severe disease.

The sample size used to generate the case report did not fully describe the pathway of cancer patients with varying types of cancers (i.e., only 10 individuals with varying cancers participated). Additionally, the relatively small sample size of participants described in the report limits the generalizability of the care report results (Sandelowski, 1995). The case report provided less information about pathways where the patient experienced a cancer recurrence, additional cycles of surgical/oncology treatment, progressing to palliative care and/or medically assisted suicide (MAID) (BCPSQC, 2019). It must also be noted that cancer pathways continually change in response to published research on treatment and patient journey maps would need to be updated to reflect these changes.

\section{Conclusion}

In summary patient journey maps can be extended to look at how a patient's healthcare journey can be improved and can form a useful tool in describing integration of technology into the journey as well as having potential for assisting in formulating digital health strategy. The ultimate objective of this work is to decrease fragmentation of care and decrease wait times. Such tools can help to identify health systems level technologies that could be used to address gaps and fragmentation in care. There is a need to incorporate within the patient journey technologies that could provide patients and caregivers with information about technological advances, tools and potentials. For example, patient journey maps could be included in patient portal systems to provide this additional information. As well, time sensitive alerts and reminders could be added to alert health professionals, caregivers and patients about wait times exceeding evidencebased norms and loss of information/communication of information that could lead to fragmented care throughout the patient journey. There are many other potential 
technological solutions that could be considered within the context of the patient journey map. The work reported in this article represents an important initial step towards a systematic consideration of such integration within the perspective of the patient and their journey through the healthcare process.

\section{Author Statement}

The authors declare that they have no conflict of interest.

\section{ORCID}

Elizabeth M. Borycki (iD) https://orcid.org/0000-0003-0928-8867

Andre W. Kushniruk (D) https://orcid.org/0000-0002-2557-9288

Evangeline Wagner (iD https://orcid.org/0000-0002-0730-9073

Ryan Kletke (D) https://orcid.org/0000-0002-0576-9789

\section{References}

Ash, J. S., Sittig, D. F., Poon, E. G., Guappone, K., Campbell, E., \& Dykstra, R. H. (2007). The extent and importance of unintended consequences related to computerized provider order entry. Journal of the American Medical Informatics Association (JAMIA), 14(4), 415-423.

BCPSQC. (2019). Journey mapping in cancer care. BC Patient Safety \& Quality Council. Vancouver, BC, Canada. Retrieved from https://bcpsqc.ca/wpcontent/uploads/2019/01/Journey-Mapping-Cancer-interactive.pdf

Borycki, E. (2019). Quality and safety in eHealth: The need to build the evidence base. Journal of Medical Internet Research, 21(12): e16689.

Catley, C., McGregor, C., Percival, J., Curry, J., \& James, A. (2008). Multi-dimensional knowledge translation: enabling health informatics capacity audits using patient journey models. In Proceedings of the 30th Annual International Conference of the IEEE Engineering in Medicine and Biology Society. IEEE.

Chaudhry, B., Wang, J., Wu, S., Maglione, M., Mojica, W., Roth, E., Morton, S. C., \& Shekelle, P. G. (2006). Systematic review: Impact of health information technology on quality, efficiency, and costs of medical care. Annals of Internal Medicine, 144(10), $742-752$.

Cresswell, K., \& Sheikh, A. (2013). Organizational issues in the implementation and adoption of health information technology innovations: An interpretative review. International Journal of Medical Informatics, 82(5), e73-e86.

Eysenbach, G. (2000). Consumer health informatics. BMJ, 320: 1713-1716.

Gagliardi, J. P., \& Turner, D. A. (2016). The electronic health record and education: Rethinking optimization. Journal of Graduate Medical Education, 8(3), 325-327.

Gill, R., \& Borycki, E. M. (2017). The use of case studies in systems implementations within health care settings: A scoping review. Studies in Health Technology and Informatics, 234, 142-149.

Greenwald, H. P. (2017). Management challenges in British Columbia's healthcare system. Journal of Health Organization and Management, 31(4), 418-429.

Guerrazzi, C. (2020). An international perspective on health information exchange: 
Adoption in OECD countries with different health care system configurations. Medical Care Research and Review, 77(4), 299-311.

Han, H. R., Gleason, K. T., Sun, C. A., Miller, H. N., Kang, S. J., Chow, S., Anderson, R., Nagy, P., \& Bauer, T. (2019). Using patient portals to improve patient outcomes: Systematic review. JMIR Human Factors, 6(4): e15038.

Health. (2020). Health. British Columbia. Retrieved from https://www2.gov.bc.ca/gov/content/health

Househ, M., Borycki, E., \& Kushniruk, A. (2014). Empowering patients through social media: The benefits and challenges. Health Informatics Journal, 20(1), 50-58.

Kalbach, J. (2016). Mapping experiences: A complete guide to creating value through journeys, blueprints and diagrams. Boston, MA: O'Reilly Media.

Khan, A., \& Anwar, Y. (2019, April). Robots in healthcare: A survey. In Proceedings of the Science and Information Conference (pp. 280-292). Cham: Springer.

Kharrazi, H., Gonzalez, C. P., Lowe, K. B., Huerta, T. R., \& Ford, E. W. (2018). Forecasting the maturation of electronic health record functions among US hospitals: Retrospective analysis and predictive model. Journal of Medical Internet Research, 20(8): e10458.

Mamlin, B. W., \& Tierney, W. M. (2016). The promise of information and communication technology in healthcare: Extracting value from the chaos. The American Journal of the Medical Sciences, 351(1), 59-68.

Martin, D., Miller, A. P., Quesnel-Vallée, A., Caron, N. R., Vissandjée, B., \& Marchildon, G. P. (2018). Canada's universal health-care system: Achieving its potential. The Lancet, 391(10131), 1718-1735.

Martin, M., Champion, R., Kinsman, L., \& Masman, K. (2011). Mapping patient flow in a regional Australian emergency department: A model driven approach. International Emergency Nursing, 19(2), 75-85.

McCarthy, S., O'Raghallaigh, P., Woodworth, S., Lim, Y. Y., Kenny, L. C., \& Adam, F. (2020). Embedding the pillars of quality in health information technology solutions using "Integrated patient journey mapping" (IPJM): Case study. JMIR Human Factors, 7(3): e17416.

Meyer, M. A. (2019). Mapping the patient journey across the continuum: Lessons learned from one patient's experience. Journal of Patient Experience, 6(2), 103-107.

OECD. (2018). Health at a glance: Europe 2018: State of Health in the EU Cycle. Retrieved from https://doi.org/10.1787/health_glance eur-2018-56-en

Parush, A. (2019). Designing health information for mutual empowerment in the joint journey of patients and healthcare professionals. Studies in Health Technology and Informatics, 257, 341-345.

Parush, A., Levin, M. L., \& Campbell, C. (2014). Dual patient-healthcare provider experience mapping and implications for information technology deployment and clinic layout. In V. Duffy \& N. Lightner (Eds.), Advances in Human Aspects of Healthcare (pp. 389-396). Boca Raton, FL: CRC Press.

Percival, J., \& McGregor, C. (2016). An evaluation of understandability of patient journey models in mental health. JMIR Human Factors, 3(2): e20.

Plsek, P. E., \& Greenhalgh, T. (2001). Complexity science: The challenge of complexity in health care. BMJ, 323(7313), 625-628.

Reid, P., \& Borycki, E. M. (2011). Emergence of a new consumer health informatics framework: Introducing the healthcare organization. Studies in Health Technology and Informatics, 164, 353-357.

Sandelowski, M. (1995). Sample size in qualitative research. Research in Nursing \& Health, 18(2), 179-183.

Santibáñez, P., Chow, V. S., French, J., Puterman, M. L., \& Tyldesley, S. (2009). Reducing patient wait times and improving resource utilization at British Columbia 
Cancer Agency's ambulatory care unit through simulation. Health Care Management Science, 12(4), 392-407.

Seljelid, B., Varsi, C., Solberg Nes, L., Stenehjem, A. E., Bollerslev, J., \& Børøsund, E. (2020). Content and system development of a digital patient-provider communication tool to support shared decision making in chronic health care: InvolveMe. $B M C$ Medical Informatics and Decision Making, 20(1): 46.

Sulieman, L., Yin, Z., \& Malin, B. A. (2020). Why patient portal messages indicate risk of readmission for patients with ischemic heart disease. In Proceedings of the AMIA Symposium (pp. 828-837).

Tierney, W. M., Rousseau, J. F., \& Khurshid, A. (2018). Measuring and managing population health. Texas Medicine, 114(2), 42-51.

Van den Bulck, S. A., Hermens, R., Slegers, K., Vandenberghe, B., Goderis, G., \& Vankrunkelsven, P. (2018). Designing a patient portal for patient-centered care: Cross-sectional survey. Journal of Medical Internet Research, 20(10): e269. doi: 10.2196/jmir.9497.

Waldemarin, R. C., \& de Farias, C. R. G. (2018). OBO to UML: Support for the development of conceptual models in the biomedical domain. Journal of Biomedical Informatics, 80, 14-25. 